\title{
Da graduação biomédica à Medicina de Família: aprendendo a se tornar um "médico da pessoa"
}

| ${ }^{1}$ Maria Inês Nogueira, ${ }^{2}$ Carla Ribeiro Guedes |

Resumo: Este estudo apresenta a educação como instância modeladora dos sistemas de representação da realidade, a partir de uma reflexão sociofilosófica desenvolvida por Kuhn, Fleck e Wittgenstein.

Através de uma pesquisa qualitativa, discute as especificidades da graduação biomédica e a formação de residentes em um Programa de Medicina de Família e da Comunidade como um processo de translação do olhar. No discurso dos residentes entrevistados, duas conclusôes se destacaram: a inadequação da formação biomédica para a resolução dos problemas de saúde da população na atenção básica; e a necessidade de uma reorientação do olhar do profissional para o "sujeito doente" e suas subjetividades, para que ele possa se tornar um "médico da pessoa".

> Palavras-chave: educação médica; racionalidade biomédica; Medicina de Família e Comunidade; subjetividade.

\footnotetext{
1 Médica; doutora em Saúde Coletiva; professora adjunta do Departamento de Planejamento em Saúde do Instituto de Saúde da Comunidade da Universidade Federal Fluminense (ISC/UFF). Endereço eletrônico: minogueira2@ gmail.com

2 Psicóloga; doutora em Saúde Coletiva; professora adjunta do Departamento de Psicologia da Universidade Federal Fluminense - Polo Universitário Rio das Ostras (UFF/PURO). Endereço eletrônico: carla. rguedes@gmail.com
} 


\section{Introdução}

Neste estudo, trabalhamos com a noção de que a educação é modeladora dos sistemas de representação da realidade. Ancoramos esse pressuposto em uma reflexão sociofilosófica a partir dos referenciais de Kuhn, Fleck e Wittgenstein. De acordo com essa linha de raciocínio, todo processo de aprendizagem encontrase condicionado por um paradigma, ou um estilo de pensamento, e ocorre por meio de exemplos e de manuais, com ênfase no treinamento, nos exercícios e na repetição. Podemos dizer, então, que todo aprendizado se dá através de uma necessária reorientação do olhar, e que esse novo olhar poderá desencadear uma modificação de conduta no aprendiz.

No entanto, em relação à formação médica, é preciso acrescentar que a transmissão de conhecimentos teóricos ou práticos através de livros, textos ou manuais, sem que haja uma vivência individual dos alunos sobre os casos que surgem na prática clínica, mostra-se insuficiente. Os períodos de treinamento prático são fundamentais para o desenvolvimento da capacidade crítica e reflexiva do estudante.

Nessa perspectiva, compreender o processo formador como um modo distinto de ver e interpretar a realidade possibilita a identificação de obstáculos epistemológicos às mudanças no ensino médico. A supervalorização da "lesão orgânica" em detrimento do sujeito doente, característica marcante da formação biomédica, reproduzida na prática médica atual, pode ser considerada um produto do treinamento dos estudantes, na medida em que essa é a ideia central que orienta o paradigma biomédico (CAMARGO JR., 1992; 2003).

Ao longo dos últimos cinquenta anos, surgiram movimentos com o objetivo de resgatar o "sujeito doente", trazendo-o para o centro das atenções. Muitos deles originaram-se no interior da própria Medicina, como a Medicina Psicossomática, enquanto outros emergiram da Psicanálise e da área da Saúde Coletiva. Entretanto, a conceituação de doença como "lesão orgânica", e a posterior reificação dessa categoria, mostrou-se uma ideia tão poderosa que justificou a utilização por Perestrello (2006) de um pleonasmo - "medicina da pessoa" - em substituição ao adjetivo "psicossomática", na denominação de sua proposta fenomenológico-existencial.

Em um estudo antropológico sobre construção de identidade profissional, Bonet (2003) propõe que a Medicina de Família seria uma "medicina da pessoa". 
Reiteramos essa associação ao discutirmos a formação do médico de família neste artigo.

\section{A educação como instância modeladora dos sistemas de representação da realidade}

$\mathrm{Na}$ discussão a seguir, utilizaremos os seguintes referenciais teóricos: de Kuhn, o conceito de paradigma - como exemplos compartilhados - e a aprendizagem através da "percepção aprendida de semelhança"; de Fleck, os conceitos de estilo e coletivo de pensamento; e, de Wittgenstein, a noção de jogos de linguagem como "formas de vida" e o conceito complementar de conversão gestáltica.

Kuhn destaca a educação e o processo pedagógico como modeladores dos sistemas de representação da realidade, ao contrário da epistemologia tradicional, que considera a educação como decorrência do método abraçado. Para o autor, as matrizes disciplinares não são aprendidas através de um receituário metodológico, e, sim, através de manuais. Explica que a capacidade de reconhecer semelhanças autorizadas pelo grupo é a principal aprendizado dos estudantes de ciência ao resolver problemas. Argumenta, então, que na aquisição e no armazenamento do conhecimento, a estratégia baseada na elaboração de fronteiras e regras não é a única à disposição para o processamento de dados ou de estímulos. Existe uma alternativa - a chamada "percepção aprendida de semelhança" -, amplamente usada na aprendizagem da linguagem, da educação ou de práticas científicas (KUHN, 1977).

Ao discutir a educação científica sob a ótica de um paradigma, ou seja, de como um modo de ver se vincula a um modo de viver, Kuhn afirma que uma mudança de paradigma equivale praticamente a abraçar uma nova forma de vida. Cita, então, o exemplo da figura de ilusão de ótica, que ora é vista como pato, ora como coelho, e observa que, no caso da mudança de paradigma, não se passa de uma maneira de ver para outra constantemente. Quando se é treinado a ver um pato por muito tempo, é necessária uma reavaliação de princípios e pressupostos para que se habilite a ver um coelho (OLIVA, 1994).

Fleck (1986) é considerado o pioneiro da abordagem sociológica no estudo do conhecimento científico, das comunidades científicas e práticas dos cientistas. No seu principal trabalho teórico, A gênese e o desenvolvimento de um fato científico, utiliza a Medicina como objeto de estudo devido às suas 
duas particularidades frente a outras disciplinas científico-naturais. A primeira dessas particularidades consiste no fato da Medicina ser um conhecimento dirigido às anormalidades. A outra consiste no caráter pragmático da Medicina, na sua permanente e imediata necessidade de êxito.

Fleck "sociologiza" a análise da ciência e distingue três tipos de fatores sociais influentes na atividade cognitiva:

1) O peso da formação: os conhecimentos se compõem, em sua maior parte, do aprendido, e não do novo. A transmissão de conhecimento, durante o processo de aprendizagem, se produz de forma imperceptível e se transforma ao passar à outra pessoa.

2) A carga da tradição: todo conhecer novo está conformado ao já conhecido.

3) A repercussão da sucessão do conhecer: somente tendo em conta as condições sociais e culturais do conhecer é possível compreender a aparição de outras muitas "realidades" junto à estabelecida pelas ciências naturais (FLECK, 1986).

Como instrumentos para compreender essa qualidade do conhecer, Fleck (1986) cria os conceitos de "coletivo de pensamento" e "estilo de pensamento". O primeiro designa a unidade social da comunidade de cientistas de um campo determinado; o segundo, as pressuposiçōes de acordo com um estilo sobre as quais o coletivo constrói seu edifício teórico. Assim, segundo o autor, o observar e o ver formativos, unidos a um estilo de pensamento, ou seja, a disposição para a percepção orientada, constituem a raiz de todo estilo de pensamento.

A introdução em um campo de conhecimento é mais um doutrinamento do que um estímulo do pensamento crítico-científico para Fleck (1986): "Toda introdução didática é, portanto, um conduzir-dentro, uma suave coerção". Assim, a comunidade formada pelos "introduzidos" adquire um "sentimento de solidariedade intelectual”. A tradição, a formação e o costume são os fatores que dão origem a uma disposição a perceber e atuar conforme um estilo e a decidir de forma dirigida e restringida. A assimilação da informação recebida pelos membros do coletivo produz os estímulos necessários para a transformação do estilo de pensamento (FLECK, 1986).

O conhecer não é um processo individual de uma teórica "consciência em geral", mas sim o resultado de uma atividade social, já que o estado de conhecimento de cada momento excede a capacidade de qualquer indivíduo. Seguindo o raciocínio de Fleck, a frase "alguém conhece algo" exige um 
suplemento análogo, por exemplo: "sobre a base de um estado determinado de conhecimento"; ou melhor, "como membro de um meio cultural determinado"; ou, melhor ainda, "em um estilo de pensamento determinado, em um determinado coletivo de pensamento" (FLECK, 1986).

A teoria dos “jogos de linguagem”, de Wittgenstein, apoiada numa semântica finitista, conduz à afirmação do caráter convencional de todo conhecimento. Mas, segundo Wittgenstein, não são decisões arbitrárias dos indivíduos que determinam o que é convencional; as convenções linguísticas estão ancoradas em padrões de atividade coletiva - "formas de vida". Essa abordagem dos problemas da cognição conduz à rejeição de toda a análise do conhecimento fundada em um "princípio de racionalidade", concebido como atributo individual, independente das relações sociais (PALÁCIOS, 1994).

Segundo Wittgenstein, a capacidade humana de processar informaçôes e julgar situações depende do estabelecimento de uma ordem cognitiva prévia. As pessoas aprendem uma linguagem através de treinamento. A conversa do dia a dia recicla, atualiza e rotiniza o emprego correto da linguagem. Os jogos de linguagem são, portanto, construções linguísticas em aberto. A aceitação dessa proposição implica o descrédito de toda tentativa de explicação das mudanças que ocorrem na esfera do conhecimento como consequência de uma lógica de argumentação verbal. Para Wittgenstein, os jogos de linguagem são sistemas completos de comunicação humana, porque se referem a "formas de vida" concretas, atendendo às necessidades dos que delas participam. Tal como a vida, eles se encontram em processos contínuos de mudança. Porém, o jogo não muda por conta de exigências lógicas ou regras abstratas de aplicação conceitual, mas porque os homens não cessam de inovar (PALÁCIOS, 1994).

Enfim, podemos perceber a existência de um fio condutor unindo o pensamento desses três autores: a capacidade para reconhecer semelhanças autorizadas pelo grupo, ou seja, o caráter convencional de todo conhecimento, é um dos principais critérios utilizados na aprendizagem da linguagem, da educação ou de práticas científicas, admitindo-se não haver fronteiras rígidas entre os diversos tipos de conhecimento.

A seguir, de forma compatível com os propósitos deste artigo, discutiremos a formação biomédica e as especificidades da formação em Medicina de Família e da Comunidade. 


\section{A formação biomédica}

Em Natural, Racional, Social: razão médica e racionalidade científica moderna, Madel Luz afirma que a Medicina incluiu-se na racionalidade científica moderna ao instituir a doença e o corpo como objetos. Através do deslocamento epistemológico de uma arte de curar indivíduos doentes para uma disciplina das doenças, a Medicina ocidental tornou-se definitivamente uma "ciência das doenças" (LUZ, 1988).

De forma similar, Camargo Jr. (2003) mostra que há uma vinculação do "imaginário científico" da Medicina contemporânea à racionalidade científica da mecânica clássica, que pode ser delineada em três proposiçôes: caráter generalizante, mecanicista e analítico. $\mathrm{O}$ primeiro diz respeito à produção de discursos com validade universal, propondo modelos e leis de aplicação geral e não se ocupando de casos individuais. Em decorrência das generalizações, ocorre uma tendência a naturalizar as máquinas produzidas pela tecnologia humana, passando o "universo" a ser entendido como uma máquina, subordinada a princípios de causalidade linear traduzíveis em mecanismos e, portanto, assumindo um caráter mecanicista. Por fim, o caráter analítico se expressa na abordagem teórica e experimental adotada para a elucidação das "leis gerais", a qual pressupõe que as partes sejam isoladas e que o funcionamento do todo é necessariamente dado pela soma destas.

A partir da epistemologia comparativa de Fleck, Camargo Jr. analisa a possibilidade de aplicação dos conceitos de "estilo e coletivo de pensamento" ao campo da Medicina, considerando que as instituições, o conhecimento e a prática médica encontram-se permeados por um estilo de pensamento específico. Apesar de haver diferenças extremas no interior desse campo, Camargo Jr. afirma que se pode esboçar uma descrição do que se chamaria de um estilo de pensamento médico. Mesmo assim, faz uma ressalva importante, ao afirmar que os médicos não são cientistas por não estarem envolvidos com a produção de conhecimento de acordo com as práticas institucionais da ciência. Os médicos são similares aos "leigos educados" descritos por Fleck, pois não possuem as ferramentas necessárias para efetivamente criticar o que lhes é apresentado pelas várias áreas disciplinares que constituem o campo de conhecimento biomédico (CAMARGO JR., 2003).

Assim, seguindo a argumentação proposta pelo autor para delinear o estilo de pensamento biomédico, considera-se que o processo de escolarização que 
transforma o estudante de Medicina num médico é uma inculcação organizada,

não apenas de conteúdos cognitivos, mas também de um modo distinto de definir o que a "realidade" é (ATKINSON, 1997). O aprendizado do médico é integrado num sistema de opiniões que resiste fortemente aos desafios, criando uma "harmonia das ilusōes", nos dizeres de Fleck (1986).

Do mesmo modo, Good (2005) demonstra como o estudante passa por uma série de "processos formativos", que o faz incorporar o objeto da Medicina, fundamentalmente biológico. Não que as dimensões experienciais ou comportamentais sejam ignoradas pelo bom clínico, mas são entendidas como separadas do "real" objeto da prática médica. Sendo assim, esse aprendizado requer a entrada em um mundo novo, em um sistema de realidade diferente, que implica novas formas de ver, escrever e falar. Como descreveu uma jovem do segundo ano de Medicina:

\footnotetext{
A escola médica é muito pesada... é uma experiência emocional intensa... quando você disseca um cérebro você tem que interagir com as informações e com seus próprios sentimentos... eu sinto que estou mudando o meu cérebro todo dia, moldando-o num caminho muito específico... (GOOD, 2005, p. 65).
}

Bonet (1999) também descreve o processo de modelação de subjetividade sofrido pelo médico residente - que implica em incorporar e aceitar os princípios estruturadores da biomedicina. De acordo com o autor, a prática biomédica se estrutura entre os domínios do saber (racional, científico) e do sentir (emocional, psicológico). Assim, a aprendizagem, bem como o habitus do trabalho médico, ocorrem às custas de uma tensão estruturante entre os polos ideológico (do saber) e sensorial (do sentir). Como na tradição biomédica "o saber" seria o polo dominante, o outro polo - "o sentir" - seria relegado a um segundo plano, com consequências indesejáveis para a prática clínica.

\section{A Medicina de Família e da Comunidade}

De acordo com a narrativa foucaultiana sobre $O$ nascimento da clínica (1980), o "olhar anatomoclínico" estrutura a formação biomédica. Por outro lado, as propostas de reorientação da formação profissional em saúde, alinhadas à "Estratégia Saúde da Família" enfatizam a necessidade de se construir um "olhar ampliado" dos profissionais médicos sobre o "sujeito doente" - um olhar que ultrapasse a ótica estritamente biológica, visando a uma melhor resolutividade 
dos problemas de saúde da população. Enfim, uma reconsideração, tanto das subjetividades presentes no complexo processo do adoecer humano, quanto da Medicina como prática relacional (NOGUEIRA, 2009; 2012).

Partindo das premissas humanizantes trazidas pela área de Saúde Coletiva, os Programas de Residência de Medicina de Família e da Comunidade propõem uma formação diferenciada, cujo objetivo é favorecer a construção de uma prática clínica integradora das dimensões biopsicossociais do adoecimento. Nas palavras de Anderson et al. (2008, p. 32): “é necessário desenvolver competências que transcendam o paradigma biomédico que, centrado na teoria biotecnológica das doenças, privilegia a dimensão fisiopatológica do processo saúde-adoecimento".

Favoreto (2004) apresenta as narrativas dos pacientes como um importante instrumento de trabalho a ser incorporado na clínica médica: "as narrativas que as pessoas constroem e trazem para o encontro clínico são uma forma de expressar as necessidades sentidas e valorizadas em seu cotidiano" (2004, p. 216). Ao integrálas à clínica, não só como uma ferramenta diagnóstica (como ocorre na clínica tradicional), mas como um elemento terapêutico e de resgate da autonomia do paciente frente ao adoecer, pode se permitir que os sujeitos envolvidos no cuidado reestruturem novas formas e normas de vida, saúde e prazer.

Os resultados de pesquisas realizadas com médicos do Programa de Saúde da Família mostram que o desenvolvimento da competência narrativa, se estruturada como um saber na clínica, poderá proporcionar uma ampliação do universo dialógico e interpretativo dos médicos. Essas questōes indicam pistas importantes para se pensar a formação médica e a educação permanente dos profissionais de saúde, sobretudo aqueles inseridos na atenção básica (FAVORETO, 2007).

Segundo Bonet (2003), os êxitos da Medicina ocidental moderna foram alcançados em detrimento de uma visão total da pessoa. Ao mesmo tempo, no interior da própria Medicina, surgiram movimentos que tentavam recuperar uma "medicina da pessoa". Nesse sentido, a Medicina de Família procuraria retomar esse caminho da totalidade e o faria utilizando novos paradigmas, mas também resgatando velhas ideias. Assim, ao se defender um enfoque que prioriza a totalidade ou a integralidade do paciente, a formação do médico de família não poderia focalizar somente a doença. O médico de família se converteria em um promotor da saúde das pessoas, em um "médico da pessoa". 
Apresentaremos, em seguida, uma discussão que aborda as peculiaridades da formação médica nos cenários do hospital e da atenção básica.

\section{Cenários de formação médica: atenção hospitalar $\mathrm{x}$ atenção básica}

Em $O$ nascimento do hospital, Foucault (1979) nos mostra que o hospital como instrumento terapêutico é uma invenção relativamente nova, do final do século XVIII. Além de se tornar um lugar de cura, ele também passa a ser um lugar de formação de médicos, e a clínica aparece então como dimensão essencial do hospital. Desde então, este se tornou e continua sendo a principal estrutura institucional da biomedicina por excelência, a despeito das variações locais, sendo considerado por alguns autores como o "templo da ciência" (HELMAN, 2003).

Entretanto, segundo Starfield (2002), um sistema de saúde com forte referencial na Atenção Primária à Saúde é mais efetivo e satisfatório para a população, tem menores custos e é mais equitativo - mesmo em contextos de grande iniquidade social. Uma evidência que fortalece a argumentação sobre a importância desses serviços como eixos orientadores da organização dos sistemas de saúde (e também da educação médica) encontra-se no clássico estudo de White, publicado no New England Journal of Medicine no início da década de 60 - "The ecology of medical care" (1961).

No contexto brasileiro, na década de 90, foi adotada pelo Ministério da Saúde uma estratégia de reorientação do modelo assistencial com ênfase na atenção básica - a Estratégia Saúde da Família -, com a finalidade de responder às necessidades da população de forma mais abrangente.

De acordo com Campos e seus colaboradores (2008), a atenção básica deveria ser uma das principais portas de entrada para o sistema de saúde, pois através dela podem ser resolvidos $80 \%$ dos problemas da população (WHO, 1978). Não obstante, o hospital ainda é o espaço hegemônico de formação dos profissionais de saúde. Essa presença marca as competências dos profissionais, mesmo quando eles trabalham na atenção básica. Cunha (2005) mapeia alguns campos em que as diferenças entre o hospital e a atenção básica são mais evidentes: as relações de poder, os diferentes saberes, o imaginário social, as relações terapêuticas e a percepção de danos. 
Conforme argumenta Cunha (2005), as condições de assimetria entre profissionais de saúde e pacientes produzidas pela instituição hospitalar não se reproduzem na atenção básica, onde, a partir da implementação da adscrição da clientela por equipe, não existe um encontro eventual com o doente em situação de isolamento, mas encontros seguidos no tempo, em situação de concorrência da intervenção terapêutica com as "intervenções da vida". Além disso, o pressuposto implícito trazido da formação hospitalar de que a centralidade do trabalho em saúde está nos procedimentos, exames e medicações adequados a cada patologia fica extremamente abalado na atenção básica. O poder do médico e dos outros profissionais de saúde e a submissão do Sujeito doente são infinitamente menores. $\mathrm{Na}$ atenção básica, torna-se impossível intervir efetivamente sem conquistar a participação e a compreensão das pessoas.

No que diz respeito aos saberes, Cunha (2005) afirma que o hospital é um espaço extremamente adequado aos instrumentos teóricos da biomedicina, que privilegia o olhar sobre o corpo, dividindo-o em pedaços estanques (especialidades) e desconsidera os aspectos psíquicos, culturais e sociais do indivíduo doente. A gravidade da situação orgânica permite que o aspecto biológico se destaque, fornecendo uma sensação de suficiência para o saber biomédico. O quanto possível, o Sujeito está isolado - bem ao contrário do que acontece na atenção básica, em que um Sujeito complexo, permeável a toda sorte de influências internas e externas, apresenta suas demandas. $\mathrm{Na}$ atenção básica, a convivência com a incerteza é maior e pode gerar grande ansiedade no profissional de saúde; nela, o diagnóstico não é uma atividade suficiente, nem sequer a mais complexa. Ao contrário, no hospital - cultura institucional em que predomina a ideia de "produção da ciência" -, há uma valorização do diagnóstico em relação à terapêutica, como aponta Camargo Jr (2003).

Ao discorrer sobre o imaginário social, Cunha (2005) afirma que, enquanto no hospital simbolicamente impera o medo da morte, na atenção básica impera a vontade de viver. A tolerância dos usuários com os efeitos colaterais, custos e limitações impostas pelo tratamento é muito menor na atenção básica. Por conta disso, a complexidade do projeto terapêutico aumenta, o que requer negociaçôes na própria conduta medicamentosa. Esse tipo de postura é raro no ambiente hospitalar, mas é quase a regra na atenção básica. A expectativa de "salvar vidas", característica do hospital, é substituída na atenção básica pela dificuldade de se reconhecerem as reais necessidades das pessoas. 
No que concerne às relações terapêuticas, os critérios de internação e alta dentro de um hospital definem os objetivos dos profissionais e, consequentemente, o tempo de contato da equipe com o doente. Esses critérios e tempos produzem expectativas, prioridades e uma certa sensação de eficácia. O pronto-socorro é capaz de atender infinitas vezes um hipertenso em crise, sem fazer intervenções para evitar a recorrência, e manter, ainda assim, a sensação de eficácia. Por outro lado, uma equipe na atenção básica que levasse seis meses para ajudar um paciente com hipertensão grave há cinco anos a controlar sua pressão arterial poderia se considerar muito eficaz. São, portanto, "tempos diferentes”, mas a formação intra-hospitalar é intrinsecamente imediatista e não facilita o aprendizado de um raciocínio clínico e a realização de projetos terapêuticos de médio e de longo prazo (CUNHA, 2005).

Finalmente, ao avaliar a percepção de danos, Cunha (2005) ressalta que, apesar de se saber que um percentual significativo de pacientes hospitalizados virá a sofrer algum tipo de dano - e de esse fato até ser "estatisticamente esperado" -, a percepção dos danos dentro do hospital é muito menor, tanto pelo pouco tempo de contato com o paciente quanto pela naturalização de alguns danos (por exemplo, a pneumonia de um idoso internado). O paradigma biomédico, com seu princípio analítico fragmentador, convive bem com o imediatismo hospitalar. Ou seja, dentro do hospital, a fragmentação do cuidado por especialidades é intensa, de forma que, à medida que aparecem outras doenças, o paciente vai sendo "fatiado" por interconsultas que se responsabilizam por pedaços cada vez menores. Outro fator que agrava essa situação é a inexistência no hospital de um seguimento longitudinal (com vínculo terapêutico) que possibilite essa percepção. Por outro lado, na atenção básica, é mais fácil perceber danos, principalmente em modelos de atenção que propiciem e valorizem o seguimento e a adscrição de clientela.

Encerramos este tópico, referente às peculiaridades dos cenários de formação nos âmbitos da atenção hospitalar e da atenção básica, com as palavras de Cunha:

Embora a clínica na Atenção Básica seja muito complexa, não só pela necessidade de entender o Sujeito (e não somente seu corpo), mas também pela necessidade da negociação da terapêutica, as corporações (especialmente a médica) tendem a negar essa complexidade. A superação dessa dificuldade institucional da Atenção Básica passa certamente pela aquisição e compreensão de uma diversidade de ferramentas e conhecimentos até certo ponto estranhos à Biomedicina, nascida e criada no hospital. (CUNHA, 2005, p. 37) 


\section{Metodologia}

Para conhecer o processo de formação de residentes de Medicina da Família e da Comunidade, desenvolvemos uma pesquisa qualitativa em um Programa de Residência de Medicina de Família e da Comunidade de uma importante universidade localizada no estado do Rio de Janeiro.

No período de março a julho de 2008, foram realizadas entrevistas em profundidade, de caráter semiestruturado, com os quatro estudantes que compunham o programa de residência, sendo duas com médicos do primeiro ano de residência e duas com médicos do segundo ano. Os residentes do primeiro ano eram egressos de uma mesma faculdade de Medicina particular do município do Rio de Janeiro, e as do segundo ano, oriundas de uma mesma faculdade de Medicina de uma universidade pública do mesmo município.

Dos quatro residentes do programa, havia três mulheres e um homem. O tempo de graduação na época da realização da entrevista variou de dois a quatro anos, e a idade dos residentes, de 25 a 29 anos.

As entrevistas ocorreram em salas do ambulatório da unidade básica que serviam de espaço para as atividades da residência. A duração das entrevistas, não preestabelecida, foi, em média, de uma hora e trinta minutos a duas horas aproximadamente. Os entrevistados mostraram-se bastante disponíveis durante as entrevistas. Todas foram autorizadas pelos participantes através do Termo de Consentimento Livre e Esclarecido, registradas através de gravação em áudio e transcritas na íntegra. Os textos passaram por pequenas correções linguísticas, com o cuidado de não eliminar o caráter espontâneo das falas.

No tratamento do material empírico que emergiu no trabalho de campo, utilizamos como referência a análise de conteúdo de Bardin (1979), através da técnica de análise temática ou categorial, que se baseia em operações de desmembramento do texto em unidades, visando descobrir os diferentes núcleos de sentido que constituem a comunicação para, posteriormente, agrupá-los em classes ou categorias. Para análise desse material empírico, recorremos ao referencial teórico que embasa este estudo: as reflexões sociofilosóficas de Kuhn, Fleck e Wittgenstein.

A partir do discurso dos residentes, foram selecionadas as seguintes categorias: 1) Lacunas na graduação biomédica; 2) O impacto do novo cenário; 3) As especificidades do olhar da atenção básica; 4) Os impasses da nova formação; e 5) $\mathrm{O}$ ensino das tecnologias relacionais. 
A pesquisa foi devidamente aprovada pelo Comitê de Ética do Instituto de Medicina Social da Universidade do Estado do Rio de Janeiro.

\section{Discussão dos resultados}

\section{Lacunas na graduação biomédica}

Os residentes foram unânimes em apontar as lacunas de uma formação que tem como cenário principal o hospital geral. Uma das entrevistadas associou o fato de a formação ocorrer num hospital de nível terciário, voltado para a assistência especializada, com as dificuldades para um acompanhamento sequencial interativo do processo de adoecimento dos pacientes:

A minha graduação foi toda no hospital, é um hospital de nível terciário, com um paciente que tinha coronariopatia, tinha hepatite, tinha uma síndrome, um lúpus... Eu me sentia impotente, os pacientes morriam muito e eu não participava do processo da doença do paciente... (R1).

Outra residente aponta a ênfase na atenção terciária em detrimento da atenção primária:

Eu acho que é uma falha o fato da graduação ser na atenção terciária e a gente ter muito pouco contato com a atenção primária. Os alunos saem de lá sabendo tudo de lúpus, mas não sabem fazer um pré-natal de baixo risco! (R1).

Um dos residentes assinala que o modelo de formação centrado no hospital e na categoria "doença" deixa de abordar temas relevantes para o exercício de uma clínica ampliada, como, por exemplo, lidar com a experiência existencial da morte:

Eu acho que a principal lacuna é esse modelo da universidade que você faz o seu treinamento todo no hospital... É um treinamento deficitário, porque eu acho que ele não te prepara para questões médicas importantes, como a questão da finitude, a morte... Só se fala de doença e fala-se muito pouco de acompanhamento da doença... (R2).

Outras questōes foram abordadas pelos residentes, tais como a pouca ênfase dada à escuta do indivíduo doente e seu contexto de vida. Como ilustra a fala abaixo:

A prática ambulatorial é muito pequena, e você tem muito pouca discussão sobre a questão do olhar a pessoa, do acolhimento, dessas outras questões que interferem na saúde, nas questôes sociais, de como abordar, de como ouvir... (R1).

Uma das entrevistadas aponta a grande lacuna da formação biomédica - a ausência de treinamento para a escuta, o acolhimento e o cuidado do indivíduo doente: 
Eu acho que a gente não é treinado mesmo para essa relação médico-paciente, de você lidar com determinadas situações que envolvem questōes mais subjetivas, de você ser o cuidador de alguém. Faz muita falta a discussão de casos, não no modelo biomédico, mas de uma forma mais ampla... (R2).

\section{O impacto do novo cenário}

Alguns residentes apontaram as principais diferenças entre o modelo hospitalocêntrico da graduação e o modelo da atenção básica na residência de Medicina de Família e da Comunidade. Há um destaque para o papel ativo a ser desempenhado na atenção básica. Como declarou uma das entrevistadas:

A graduação de Medicina é hospitalocêntrica. Você é o médico que está dentro do hospital, ou do ambulatório, e o paciente vem até você. E a proposta da Medicina de família é outra: nós vamos até a casa do paciente, nós interferimos na qualidade de vida dele, queremos saber como ele está vivendo... Acho que a diferença básica na graduação é essa... primeiro você é passivo, agora você é ativo. (R2).

Uma das residentes enxerga o cenário da atenção básica como facilitador de uma abordagem integral:

O cenário do hospital universitário tem muito foco em doença. A discussão com os professores e preceptores é voltada para questōes técnicas da doença. Na residência, na saúde da família, você faz um acompanhamento a longo prazo dos pacientes e discute sobre os determinantes da doença... A prática muda, as questôes avaliadas são outras, é uma abordagem integral do paciente... (R1).

Uma médica ressalta a diferença entre os enfoques teóricos abordados nos dois cenários de formação:

$\mathrm{Na}$ graduação de Medicina você adquire muitos conhecimentos técnicos; na residência, o enfoque das aulas teóricas é diferente. Estamos vendo abordagem familiar, ao paciente, estudo de território. Nada disso foi abordado na graduação! (R1).

Por sua vez, o residente do grupo percebe diferenças até mesmo na postura do médico:

$\mathrm{Na}$ graduação, o enfoque dado é que o médico está acima do bem e do mal, ele faz o diagnóstico, trata e cura. $\mathrm{Na}$ residência é muito diferente: o tempo todo os preceptores enfatizam que nós vamos acompanhar o paciente, que vamos avaliando, e a gente aprende a dizer que não sabe [...] (R2).

Os residentes foram unânimes em afirmar que a formação em uma residência de Medicina de Família e da Comunidade incorpora os aspectos sociais, culturais e psicológicos do paciente. Uma das residentes apontou que essa incorporação se dá necessariamente no locus da família: 
Eu acho que na Medicina de Família, querendo ou não, você já incorpora isso, porque

é todo um pacote: você vai na casa da pessoa, você vê a condição de vida dela. Uma coisa é a rotina da emergência, que você vê um volume maior de pacientes, mas no outro dia você nem lembra quem são eles. Outra coisa é a Medicina de Família que você está ali todo dia, que você adentra na vida da pessoa. (R1).

$\mathrm{Na}$ atenção básica, os residentes se deparam com problemas de saúde mais simples e frequentes, que não são um desafio intelectual para se fazer o diagnóstico, como nas patologias raras encontradas no hospital. Uma entrevistada mostra o seu conflito ao afirmar que as questôes subjetivas encontram-se tão presentes na prática clínica da residência que esta lhe parece, muitas vezes, uma clínica de menor importância:

Acho que a residência tem muito esse foco [de incorporação dos aspectos sociais, culturais e psicológicos]... Às vezes eu acho que a gente tem uma clínica insuficiente, menor [...] (R1).

Algumas residentes afirmaram que as dimensôes subjetivas do adoecimento poderiam ser ainda mais exploradas na residência. Uma delas cita os impasses verificados na relação médico-paciente e as falhas no desenvolvimento de competências para abordar problemas emocionais:

$\mathrm{Eu}$ acho que a gente podia ter isso de uma maneira mais profunda na residência. Um auxílio na relação médico-paciente, tanto prático quanto teórico. Nos auxiliar a como se relacionar com as questóes psicológicas dos pacientes... Eles trazem muitos problemas emocionais... (R2).

\section{As especificidades do olhar da atenção básica}

A abordagem ao paciente no seu próprio domicílio também foi um ponto bastante mencionado pelos entrevistados. As duas falas a seguir exemplificam o grau de complexidade da clínica na atenção básica:

É muito mais cômodo para você atender o paciente numa sala, onde você diz para a mãe que o neném deve ficar num lugar que não tem poeira, não tem umidade, porque senão ele vai continuar espirrando... Outra coisa é ir à casa do paciente, como fazemos aqui, e ver que é um barraquinho úmido, com cortinas que separam os cômodos e com animais convivendo com as pessoas num ambiente tão pequeno. Lidar com tanta pobreza, tanta miséria, me comove muito, é uma grande dificuldade para mim... [...] Essa adaptação ao atendimento domiciliar é difícil, você mudar a sua escuta, perguntar como vai a família, saber como está a casa. Às vezes a casa está suja e você tem que falar que ele não pode ficar num ambiente com sujeira. Você não pode falar de uma forma grosseira, tem que criar um vínculo... Você não está mais dentro do hospital, onde o paciente está deitado numa cama que você vai lá, examina e pronto. (R2). 
Um dos residentes pontuou as dificuldades da condução terapêutica em decorrência do contexto socioeconômico do paciente:

Têm remédios que não têm aqui no posto. O paciente está com uma doença infectocontagiosa, o parasita está na casa dele, ele precisa de banho, mas não tem o xampu específico para comprar e não tem a menor chance de comprar. Então você se encontra em situações que não sabe bem o que fazer... (R2).

Uma das entrevistadas menciona a dificuldade de mudar o olhar construído durante a graduação biomédica para um olhar voltado para a atenção básica:

Acho que é muito difícil mudar o olhar, ter um olhar de atenção básica! Minha graduação foi toda voltada para a enfermaria, onde você resolve tudo sobre o paciente, e ele é vigiado. Para mim ainda é difícil entender e confiar nessa relação ambulatorial, que você não vai resolver tudo naquela consulta, que as coisas podem ser a longo prazo... Mudar essa percepção do tratamento não é automático... (R1).

\section{Os impasses da nova formação}

Todos os residentes mencionaram dificuldades em definir estratégias para lidar com as questóes sociais e os aspectos emocionais dos pacientes. Uma entrevistada atribui sua postura "paternalista" a sua formação na graduação biomédica:

Eu sou um pouco paternalista... acho que é por influência da minha graduação. Lá no hospital, quando um paciente chegava, era assim: 'nós vamos resolver o seu problema'. A gente não tinha muito isso do paciente discordar do que você falava, o que você falava era lei! Eu aqui tenho muita dificuldade, a gente aprende que tem que estimular a autonomia do paciente, mas eu fico tentando dar soluçōes para o paciente, eu acho que vou conseguir resolver tudo... (R1).

Uma residente mencionou o envolvimento de aspectos espirituais nas suas estratégias para auxiliar os pacientes com questôes emocionais:

Dependendo do que ele fala, eu sou muito espiritualista e religiosa, eu sempre pergunto se essa pessoa acredita em Deus, e tento levar para essa questão do espiritual mesmo, sem entrar numa religião específica. Eu não tento colocar essa ideia que está acontecendo porque Deus quis, mas eu tento falar a respeito de resignação e pensamento positivo. Sei que o que eu faço é muito pouco... (R2).

Embora todos os residentes assumissem ter dificuldades para lidar com essas outras dimensōes do adoecimento, os quatro demonstraram ser importante a valorização da fala do paciente e da escuta do médico. Como ilustra o depoimento a seguir:

Eu tento deixar ele falar, exatamente pela questão do vínculo. Se ele tiver alguma questão emocional, tem que ter um vínculo com você... Eu tento ouvir o máximo possível... (R2). 


\section{O ensino das "tecnologias relacionais"}

Todos os entrevistados afirmaram que o ensino na residência valoriza vários elementos que compõem as "tecnologias relacionais" (MEHRY, 2002), tais como o acolhimento, o vínculo, a responsabilização e o estímulo à autonomia do paciente. As duas falas abaixo são bastante significativas sobre essa questão:

Nós fomos introduzidos aqui [na unidade básica] trabalhando o acolhimento. Fomos instruídos que receber o paciente não era ficar fixado na agenda, é escutar a demanda do paciente. (R2).

Aqui a gente ouve o tempo todo que tem que estimular a autonomia do paciente. Você vai propor alguma coisa, vai negociar com o paciente, e ele é que vai decidir ou não. (R1).

Um dos princípios organizacionais estruturantes da Estratégia Saúde da Família é a "adscrição da clientela", segundo a qual os profissionais de saúde ficam responsáveis por um setor específico da comunidade. Nesse contexto, os residentes ressaltaram que a construção do vínculo com os usuários do setor é uma questão muito enfatizada pelos preceptores, como ilustram as duas falas a seguir:

Eles [os preceptores] nos diziam que se nós não conseguíssemos fazer o vínculo, não iríamos conseguir criar o setor, iria ficar um setor perdido, e nós não íamos ter a menor chance de trabalhar aqui. (R2).

Nós quatro somos responsáveis por um setor da população. O setor começou ano passado, e nós setorizamos, cadastramos, nos responsabilizamos pelos atendimentos dos pacientes, fazemos as visitas domiciliares, enfim, nós gerenciamos o setor. (R2).

Por sua vez, a responsabilização também foi um tema bastante ressaltado no ensino. Os entrevistados mencionaram a responsabilidade de atender todo e qualquer paciente que os procure, independente de ser ou não de seu setor específico.

Nós fomos criando a nossa responsabilidade para com o usuário que tivesse aqui, independente da gente atender pessoas que são do nosso setor. Por exemplo, se é um paciente com tuberculose, que não está querendo tratar, vem aqui, não é recebido e vai embora, será uma pessoa que vai transmitir a doença e se perdeu a oportunidade de tentar tratá-lo. (R2)

O ensino das tecnologias relacionais na formação dos residentes em Medicina de Família e da Comunidade apresenta-se como um elemento importante na configuração de um agir médico diferenciado. Pois, ao contrário da clínica aprendida no ambiente hospitalar, o cenário da atenção básica requer outro tipo de clínica - uma "clínica do sujeito" (CAMPOS, 2007). 


\section{Considerações finais}

A atenção básica em saúde, com a ampliação de cenários para práticas tanto de clínica quanto de Saúde Coletiva, é um campo privilegiado de investigação e produção de conhecimento. As intervenções e experiências propiciadas pelos cenários de atenção básica são de grande complexidade, ao contrário do que imagina o senso comum. Ao permitir uma abordagem ampliada e singular de cada caso e o trabalho em equipe multiprofissional, possibilita a aquisição de competências essenciais para o exercício da profissão médica (CAMPOS et al., 2008).

Quando se articula o conhecimento aos contextos de prática profissional, a importância da introdução de novos cenários de ensino-aprendizagem na formação médica também é reforçada: "Ser capaz de aplicar um conhecimento num contexto não significa necessariamente sê-lo em qualquer outro; ao contrário, cada contexto significa uma aprendizagem, e em cada experiência transformam-se também as ideias" (RIBEIRO, 2004).

$\mathrm{Na}$ formação biomédica tradicional, duas questões se destacam durante o aprendizado da clínica: a desconsideração dos fatores não biológicos que atuam no processo de adoecimento (exaustivamente admitida) e o reconhecimento desses fatores, por parte do estudante, como estranhos à Medicina e à prática clínica (metáfora da resistência aos esforços para transformação, comumente verificada em reformas curriculares). Tais situações podem ser vistas como herança de um "olhar anatomoclínico", forjado com o advento da anatomia patológica, que privilegiou a objetivação dos problemas de saúde (NOGUEIRA, 2012).

No entanto, o ensino médico em ambiente hospitalar deve ser considerado insubstituível, embora não exclusivo. Apesar de a formação médica ser indissociável da prática clínica hospitalar, "há uma tendência atual de desospitalização dos cuidados à saúde, acompanhada por uma desospitalização do ensino" (VIEIRA, 2004).

O material empírico dessa pesquisa revelou a inadequação da formação biomédica para a resolução dos problemas de saúde da população na atenção básica. Através do discurso dos residentes, as lacunas de uma graduação médica fundamentalmente hospitalocêntrica tornaram-se visíveis, assim como os impasses gerados pela formação em um novo cenário de prática. Sem dúvida, a construção da clínica na atenção básica significa ainda um grande desafio, pois envolve uma gama de questôes subjetivas trazidas pelas relações interpessoais. 
O conceito de substituição paradigmática de Kuhn (1991) mostrou-se aplicável

ao objeto deste estudo. A contundente expressão wittgensteiniana: "abraçar uma nova forma de vida" é, de fato, percebida no discurso dos residentes entrevistados. A fala de um deles - "é muito difícil mudar o olhar, ter um olhar de atenção básica" - traduz a magnitude da transformação requerida. Assim, ao instituir o enfoque no "sujeito doente" e não apenas na "doença", a formação em Medicina de Família e da Comunidade ensina os residentes a se tornarem "médicos da pessoa".

\section{Referências}

ANDERSON, M.I.P.; RODRIGUES, R.D. Formação em medicina de família e Comunidade. Cadernos da ABEM, Rio de Janeiro, v.4, p.30-37, 2008.

ATKINSON, P. The clinical experience: the construction and reconstruction of medical reality. Adershot: Ashgate, 1997.

BARDIN, L. Análise de conteúdo. Lisboa: Ediçōes 70, 1979.

BONET, O.A.R. Saber e sentir. Uma etnografia da aprendizagem da biomedicina. PHYSIS - Revista de Saúde Coletiva, Rio de Janeiro, v.9, n.1, p.123-150, 1999.

Os médicos da pessoa. Um estudo comparativo sobre a construção de uma identidade profissional. Tese (Doutorado em Antropologia Social) - Programa de Pós-graduação em Antropologia Social, Universidade Federal do Rio de Janeiro, Rio de Janeiro, 2003.

CAMARGO JR., K.R. Paradigmas, ciência e saber médicos. Rio de Janeiro: IMS-UERJ, 1992 (Série Estudos em Saúde Coletiva, 6).

Biomedicina, saber \& ciência: uma abordagem crítica. São Paulo: Hucitec, 2003.

CAMPOS, G.W.S. A clínica do sujeito: por uma clínica reformulada e ampliada. In: . Saúde Paideia. São Paulo: Hucitec, 2007.

. GUTIÉRREZ, A.C.; GUERRERO, A.V.P.; CUNHA, G.T. Reflexōes sobre a Atenção Básica e a Estratégia de Saúde da Família. In: CAMPOS, G.W.; GUERRERO, A.V.P. (orgs.). Manual de práticas de Atenção Básica: saúde ampliada e compartilhada. São Paulo: Aderaldo \& Rothschild, 2008.

CUNHA, G.T. A construção da clínica ampliada na atenção básica. São Paulo: Hucitec, 2005.

FAVORETO, C.O. A velha e renovada clínica dirigida à produção de um cuidado integral em saúde. In: PINHEIRO, R.; MATTOS, R.A. (Orgs.). Cuidado: as fronteiras da integralidade. Rio de Janeiro: Hucitec, 2004.

- A narrativa na e sobre a clínica na Atenção Primária: uma reflexão sobre o modo de pensar e agir dirigido pelo diálogo à integralidade e ao cuidado em saúde. Tese (Doutorado em Saúde Coletiva) - Instituto de Medicina Social, Universidade do Estado do Rio de janeiro, Rio de Janeiro, 2007. 
FLECK, L. La génesis y el desarrollo de um hecho científico. Madrid: Alianza, 1986.

FOUCAULT, M. O nascimento do hospital. In: . Microfísica do poder. Rio de Janeiro: Graal, 1979.

. O nascimento da clínica. Rio de Janeiro: Forense Universitária, 1980.

GOOD, J.B. Medicine, rationality, and experience: An anthropological perspective. United Kingdom: Cambridge University Press, 2005.

HELMAN, C.G. Cultura, saúde e doença. Porto Alegre: Artmed, 2003.

HOCHMAN, G. A ciência entre a comunidade e o mercado: leituras de Kuhn, Bourdieu, Knorr-Cetina e Latour. In: PORTOCARRERO, V. (Org.). Filosofia, história e sociologia das ciências I: abordagens contemporâneas. Rio de Janeiro: Fiocruz, 1994.

KUHN, T.S. A tensão essencial. Lisboa: Edições 70, 1977.

. A estrutura das revoluçôes científicas. São Paulo: Perspectiva, 1991.

LUZ, M.T. Natural, racional e social: razão médica e racionalidade científica moderna. Rio de Janeiro: Campus, 1988.

MERHY, E.E. Saúde: cartografia do trabalho vivo. São Paulo: Hucitec, 2002.

NOGUEIRA, M.I. As mudanças na educação médica brasileira em perspectiva: reflexões sobre a emergência de um novo estilo de pensamento. Revista Brasileira de Educação Médica, Rio de Janeiro, v.2, n.33, p. 262-270, 2009 b.

. Retratos da formação médica nos novos cenários de prática. São Paulo: Hucitec, 2012.

OLIVA, A. Kuhn: o normal e o revolucionário na reprodução da racionalidade científica. In: PORTOCARRERO, V. (Org.). Filosofia, história e sociologia das ciências I: abordagens contemporâneas. Rio de Janeiro: Fiocruz, 1994.

PALÁCIOS, M. O programa forte da sociologia do conhecimento e o princípio da causalidade. In: PORTOCARRERO, V. (Org.). Filosofia, história e sociologia das ciências I: abordagens contemporâneas. Rio de Janeiro: Fiocruz, 1994.

PERESTRELlO, D. A medicina da pessoa. São Paulo: Atheneu, 2006.

RIBEIRO, E.C.O. Educação permanente em saúde. In: MARINS, J.J.N. et al. (Orgs.). Educação médica em transformação: instrumentos para a construção de novas realidades. São Paulo: Hucitec, 2004.

STARFIELD, B. Atenção primária: equilíbrio entre necessidades de saúde, serviços e tecnologia. Brasília: Ministério da Saúde, 2002.

VIEIRA, J.E. O processo de aprendizagem em hospitais de ensino. In: MARINS, J.J.N. et al. (Orgs.). Educação médica em transformação: instrumentos para a construção de novas realidades. São Paulo: Hucitec, 2004. 
WHITE, K.L.; WILLIAMS, T.F.; GREENBERG, B.G. The ecology of medical care. $N$ Engl J Med., v.265, p. 885-92, 1961.

WORLD HEALTH ORGANIZATION. Primary Health Care. Genebra: WHO, 1978.

\section{Nota}

${ }^{1}$ As autoras participaram igualmente de todas as etapas de elaboração do artigo. 


\section{Abstract}

From biomedical graduation to Family

Medicine: learning to become a "person's doctor"

This paper introduces education as sign of reality

representation of modeling systems starting from a

socio-philosophical reflection developed by Kuhn,

Fleck and Wittgenstein. Through a qualitative research, we discussed biomedical graduation and residence graduation specificities in a Family Medicine Program and the Community, as a process to change this view. During the interview with medicine residents, in their discourse, two conclusions emerged: the inadequation of the biomedical formation to solve population health care issues involving basic attention and the need to a reorientation to the "sick subject" and their subjectivities to become a "person's doctor".

> Key words: medical education; biomedical rationality; community and family doctor; subjectivity. 